\title{
Optimization of Multiple Roughness Characteristics of Chemically Deposited Ni-P-W Coating Using Weighted Principal Component Analysis
}

\author{
Supriyo Roy and Prasanta Sahoo \\ Department of Mechanical Engineering, Jadavpur University, Kolkata 700032, India \\ Correspondence should be addressed to Prasanta Sahoo, psjume@gmail.com
}

Received 16 May 2012; Accepted 11 June 2012

Academic Editors: K. Ismail and J.-L. Lataillade

Copyright (C) 2012 S. Roy and P. Sahoo. This is an open access article distributed under the Creative Commons Attribution License, which permits unrestricted use, distribution, and reproduction in any medium, provided the original work is properly cited.

\begin{abstract}
The present investigation deals with the chemical deposition of Ni-P-W coating on mild steel substrate and optimization of multiple surface roughness characteristics on the basis of different coating process parameters. Three coating parameters which are varied to have the optimum condition are concentration of nickel source, concentration of reducing agent, and concentration of tungsten source. Five different roughness parameters, namely, centre line average $\left(R_{a}\right)$, root mean square roughness $\left(R_{q}\right)$, skewness $\left(R_{\mathrm{sk}}\right)$, kurtosis $\left(R_{\mathrm{ku}}\right)$, and mean peak line spacing $\left(R_{\mathrm{sm}}\right)$ are considered. Weighted principal component analysis (WPCA) method is adopted to convert the multiple-response problem into a single performance index and Taguchi $\mathrm{L}_{27}$ orthogonal array is used. ANOVA is performed to find the significance of the each coating process parameters and their interactions. The EDX analysis, XRD analysis, and SEM are performed to study the composition and structural aspects.
\end{abstract}

\section{Introduction}

Among the different surface engineering methods, application of a coating is the most popular one. The ability to deposit hard coating on a wide range of substrate surface and still maintain adequate structural and functional properties is a very desirable objective. Coating deposition is generally carried out in an aqueous medium by electrolytic or electroless (chemical deposition) method. In this way, not only pure metals but also a wide range of alloys can be deposited. At present among the coatings deposited by aqueous means, electrolytic method enjoys the larger share compared to the electroless method. However, the potentials of electroless methods have been well recognized and they are being applied in many industrial and special applications where electrolytic method is inconvenient. Electroless/chemical deposition was introduced in 1946 by Brenner and Riddell [1]. Since then, this type of coating is used enormously as a protective coating on various types of substrate materials. Among them, the basic nickel-phosphorous binary coating has gained immense popularity due to its superior surface roughness, friction, wear, and anticorrosion characteristics
$[2,3]$. Nickel-phosphorus deposits are capable of providing wear resistance, particularly when the phosphorus content is high and when the deposits are heat-treated at 400$600^{\circ} \mathrm{C}$ [4]. The properties and microstructures of chemically deposited coatings depend on the amount of phosphorus alloyed in the deposit and postdeposition heat treatment. The structure of as-plated coatings has been reported to be either crystalline or amorphous, or a mixture of both [5]. A remarkable improvement in the wear resistance of the binary coating has been reported when hard particles are incorporated [6]. Another effective method to improve the properties of these coatings is alloying. Addition of a third element into the binary alloy of nickel to form a ternary alloy coating such as Ni-Cu-P $[7,8]$, Ni-P-TiO2 $[9,10]$, and Ni-W-P [11, 12] has been studied. Pearlstein et al. [13] first presented the Ni-P-W ternary alloy in 1963 and since then, many investigations on Ni-W-P ternary alloy were reported. As tungsten, a refractory metal itself cannot be deposited from any aqueous solution. However, tungsten alloys with the iron group transition metals can be readily deposited from aqueous solutions containing tungsten ion [14]. The incorporation of tungsten in to the nickel matrix 
led to the solute hardening, enhanced the hardness, and exhibited excellent properties such as mechanical properties, tribological properties, and corrosion resistance. Another important aspect of this type of coating is surface roughness which has to be maintained within a tolerable range.

Surface roughness determines how the real object will interact with the mating surface. Usually, rough surface corresponds to high friction and wear than the smooth surface. So minimization of roughness is needed. It has been observed from literature review that most of the investigators focus on the centre line average roughness $\left(R_{a}\right)$ of the coated surface. However, a surface generated by machining is composed of a large number of length scales of superimposed roughness [15] which are generally characterized by three different types of parameters, namely, amplitude parameters, spacing parameters, and hybrid parameters. Thus, it is not sufficient to describe the surface quality by considering only one parameter such as centre line average roughness $\left(R_{a}\right)$.

The present study aims to achieve a optimum combination of coating process parameters considering five different roughness parameters, namely, centre line average $\left(R_{a}\right)$, root mean square roughness $\left(R_{q}\right)$, skewness $\left(R_{\text {sk }}\right)$, kurtosis $\left(R_{\mathrm{ku}}\right)$, and mean peak line spacing $\left(R_{\mathrm{sm}}\right)$. The traditional Taguchi method focused on one characteristic to optimize and obtain a combination of parameter conditions. As the present study deals with more than one quality characteristic, the traditional Taguchi method is not suitable to optimize the problem and higher signal/noise $(\mathrm{S} / \mathrm{N})$ ratio of one response may corresponds to lower $\mathrm{S} / \mathrm{N}$ ratio of the other. So a single performance index is needed which may represent all the responses. The weighted principal component analysis (WPCA) can effectively solve the correlation problem. Here, WPCA method is adopted to convert the multivariate problem in to a single performance index then Taguchi method is employed to find the optimum coating parameter combination.

\section{Experimental Procedure}

2.1. Experimental Design. The experiment was carried out with three controllable factors of the coating process, each factor having three levels. These factors are concentration of nickel source (nickel sulphate solution, factor A), concentration of reducing agent (sodium hypophosphite solution, factor B), and concentration of tungsten source (sodium tungstate solution, factor $\mathrm{C}$ ). The five responses are the five different roughness parameters $\left(R_{a}, R_{q}, R_{\mathrm{sk}}, R_{\mathrm{ku}}\right.$, and $\left.R_{\mathrm{sm}}\right)$. Here, the full factorial experiment is replaced by a less expensive, faster, and partial factorial experiment. Taguchi's design for the partial factorial is based on specially developed orthogonal array (OA). As it is a three factor three level experiment, so the total degrees of freedom (DOF) considering the individual factors and their interactions is 18 . Thus, $\mathrm{L}_{27}$ orthogonal array is chosen as it satisfy all the DOF conditions. The standard $\mathrm{L}_{27}$ orthogonal array is shown in Table 1 . The values 1, 2, and 3 in this table indicate the levels of the factors. All the design factors with their corresponding levels are shown in Table 2.
2.2. Substrate Preparation. Mild steel (AISI 1040) specimen of size $20 \mathrm{~mm} \times 20 \mathrm{~mm} \times 8 \mathrm{~mm}$ is used to deposit the Ni-P$\mathrm{W}$ coating. Shaping, parting, and milling processes are used accordingly for the preparation of the sample. The sample is then subjected to surface grinding process. The sample is mechanically cleaned from foreign matters and corrosion products. After that the MS sample is cleaned using distilled water and a pickling treatment is given to the specimen with dilute $(50 \%)$ hydrochloric acid for one minute to remove any surface layer formed like rust followed by rinsing in distilled water and methanol cleaning. A large number of trial experiments are performed before deciding the bath composition.

2.3. Coating Deposition. Table 3 indicates the bath composition and the operating conditions for successful coating of Ni-P-W on the mild steel substrate. Nickel sulphate is used as the source of nickel while sodium hypophosphite is the reducing agent. Sodium tungstate solution is used as the source of tungsten ion. The bath is prepared by adding the constituents in appropriate sequence. The $\mathrm{pH}$ of the solution is maintained around $7-8$ by continuous monitoring with a $\mathrm{pH}$ meter. The cleaned samples are activated in palladium chloride solution at a temperature of $55^{\circ} \mathrm{C}$. Activated samples are then submerged into the chemical bath which is maintained at a temperature between 90 and $92^{\circ} \mathrm{C}$ with the help of a hot plate cum stirrer attached with a temperature sensor also submerged in the solution. The deposition is carried out for a period of 3 hours. The range of coating thickness is found to lie around 20-25 microns. After deposition, the samples are taken out of the bath and cleaned using distilled water. The electrode reactions in the deposition of ternary Ni-P-W are as follows [16]:

$$
\begin{gathered}
\mathrm{Ni}^{2+}+2 \mathrm{e}=\mathrm{Ni} \\
\mathrm{WO}_{4}{ }^{2-}+6 \mathrm{e}+4 \mathrm{H}_{2} \mathrm{O}=\mathrm{W}+8 \mathrm{OH}^{-} \\
\mathrm{H}_{2} \mathrm{PO}_{2}{ }^{-}+3 \mathrm{OH}^{-}=\mathrm{HPO}_{3}{ }^{2-}+2 \mathrm{H}_{2} \mathrm{O}+2 \mathrm{e} \\
\mathrm{H}_{2} \mathrm{PO}_{2}{ }^{-}+2 \mathrm{H}^{+}+\mathrm{e}=\mathrm{P}+2 \mathrm{H}_{2} \mathrm{O} .
\end{gathered}
$$

It is important to note that the present study does not consider the substrate roughness as the input variable. Thus, it is essential that all samples after different stages of processing and prior to coating should have the same roughness. But this is extremely difficult to achieve. Hence, large numbers of samples are prepared, and after all the processing prior to coating these are subjected to roughness evaluation (centre line average, $R_{a}$ ). Only those specimens that show insignificant variation (less than $0.1 \%$ ) in roughness are used for coating deposition.

2.4. Roughness Measurement. A portable stylus type profilometer, Talysurf (Taylor Hobson, Surtronic 3+) is used to measure the roughness of the coated surface. The profilometer is set to a cut off length of $0.8 \mathrm{~mm}$, Gaussian filter, and traverse speed $1 \mathrm{~mm} / \mathrm{s}$ with a traverse length of 
TABLE 1: $\mathrm{L}_{27}$ Orthogonal array with design factors and interactions.

\begin{tabular}{lccccccccccccc}
\hline Trial no. & 1 & 2 & 3 & 4 & 5 & 6 & 7 & 8 & 9 & 10 & 11 & 12 & 13 \\
$(\mathrm{~A})$ & $(\mathrm{B})$ & $(\mathrm{A} \times \mathrm{B})$ & $(\mathrm{A} \times \mathrm{B})$ & $(\mathrm{C})$ & $(\mathrm{A} \times \mathrm{C})$ & $(\mathrm{A} \times \mathrm{C})$ & $(\mathrm{B} \times \mathrm{C})$ & - & - & $(\mathrm{B} \times \mathrm{C})$ & - & - & 1 \\
\hline 1 & 1 & 1 & 1 & 1 & 1 & 1 & 1 & 1 & 1 & 1 & 1 & 1 & 1 \\
2 & 1 & 1 & 1 & 1 & 2 & 2 & 2 & 2 & 2 & 2 & 2 & 2 & 2 \\
3 & 1 & 1 & 1 & 1 & 3 & 3 & 3 & 3 & 3 & 3 & 3 & 3 & 3 \\
4 & 1 & 2 & 2 & 2 & 1 & 1 & 1 & 2 & 2 & 2 & 3 & 3 & 3 \\
5 & 1 & 2 & 2 & 2 & 2 & 2 & 2 & 3 & 3 & 3 & 1 & 1 & 1 \\
6 & 1 & 2 & 2 & 2 & 3 & 3 & 3 & 1 & 1 & 1 & 2 & 2 & 2 \\
7 & 1 & 3 & 3 & 3 & 1 & 1 & 1 & 3 & 3 & 3 & 2 & 2 & 2 \\
8 & 1 & 3 & 3 & 3 & 2 & 2 & 2 & 1 & 1 & 1 & 3 & 3 & 3 \\
9 & 1 & 3 & 3 & 3 & 3 & 3 & 3 & 2 & 2 & 2 & 1 & 1 & 1 \\
10 & 2 & 1 & 2 & 3 & 1 & 2 & 3 & 1 & 2 & 3 & 1 & 2 & 3 \\
11 & 2 & 1 & 2 & 3 & 2 & 3 & 1 & 2 & 3 & 1 & 2 & 3 & 1 \\
12 & 2 & 1 & 2 & 3 & 3 & 1 & 2 & 3 & 1 & 2 & 3 & 1 & 2 \\
13 & 2 & 2 & 3 & 1 & 1 & 2 & 3 & 2 & 3 & 1 & 3 & 1 & 2 \\
14 & 2 & 2 & 3 & 1 & 2 & 3 & 1 & 3 & 1 & 2 & 1 & 2 & 3 \\
15 & 2 & 2 & 3 & 1 & 3 & 1 & 2 & 1 & 2 & 3 & 2 & 3 & 1 \\
16 & 2 & 3 & 1 & 2 & 1 & 2 & 3 & 3 & 1 & 2 & 2 & 3 & 1 \\
17 & 2 & 3 & 1 & 2 & 2 & 3 & 1 & 1 & 2 & 3 & 3 & 1 & 2 \\
18 & 2 & 3 & 1 & 2 & 3 & 1 & 2 & 2 & 3 & 1 & 1 & 2 & 3 \\
19 & 3 & 1 & 3 & 2 & 1 & 3 & 2 & 1 & 3 & 2 & 1 & 3 & 2 \\
20 & 3 & 1 & 3 & 2 & 2 & 1 & 3 & 2 & 1 & 3 & 2 & 1 & 3 \\
21 & 3 & 1 & 3 & 2 & 3 & 2 & 1 & 3 & 2 & 1 & 3 & 2 & 1 \\
22 & 3 & 2 & 1 & 3 & 1 & 3 & 2 & 2 & 1 & 3 & 3 & 2 & 1 \\
23 & 3 & 2 & 1 & 3 & 2 & 1 & 3 & 3 & 2 & 1 & 1 & 3 & 2 \\
24 & 3 & 2 & 1 & 3 & 3 & 2 & 1 & 1 & 3 & 2 & 2 & 1 & 3 \\
25 & 3 & 3 & 2 & 1 & 1 & 3 & 2 & 3 & 2 & 1 & 2 & 1 & 3 \\
26 & 3 & 3 & 2 & 1 & 2 & 1 & 3 & 1 & 3 & 2 & 3 & 2 & 1 \\
27 & 3 & 3 & 2 & 1 & 3 & 2 & 1 & 2 & 1 & 3 & 1 & 3 & 2 \\
\hline
\end{tabular}

TABLE 2: Design factors and their levels.

\begin{tabular}{lcccc}
\hline Design factors & \multirow{2}{*}{ Unit } & \multicolumn{1}{c}{ Levels } \\
\hline Concentration of source of nickel (nickel sulphate solution) (A) & $\mathrm{g} / \mathrm{L}$ & 20 & $25^{\mathrm{a}}$ & 30 \\
Concentration of reducing agent (sodium hypophosphite solution) (B) & $\mathrm{g} / \mathrm{L}$ & 14 & $17^{\mathrm{a}}$ & 20 \\
Concentration of source of tungsten (sodium tungstate solution) (C) & $\mathrm{g} / \mathrm{L}$ & 15 & $20^{\mathrm{a}}$ & 25 \\
\hline
\end{tabular}

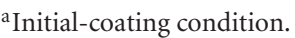

$4 \mathrm{~mm}$. Roughness measurement on the coatings is repeated for five times at different locations, and the average of five measurements is recorded. The parameter evaluations are microprocessor based. The measured profile is digitized and processed through the dedicated advanced surface finish analysis software Talyprofile for evaluation of the roughness parameters. The results are shown in Table 4.

2.5. Composition Study and Structural Aspects. Energy dispersive X-ray analysis (EDAX Corporation) is performed to determine the composition of the coating in terms of the weight percentages of nickel-phosphorous and tungsten.
The EDX analysis is done on the coatings developed from the bath consisting of different concentrations of sodium tungstate (tungsten ions) in order to capture the range of tungsten content in the coatings. Figure 1 shows the EDX spectra of the coated surface. Scanning electron microscopy (SEM) (JEOL, JSM-6360) is used on as-deposited samples in order to observe the surface morphology. The SEM image of the sample is shown in Figure 2. From the figure, it is evident that the surface is covered with globular particles with almost no porosity. The surface is optically smooth with no surface damage. An XRD analyzer (Rigaku, Miniflex) is used for the identification of phase of the compounds in the coatings. It is observed that the as deposited surface shows mostly 


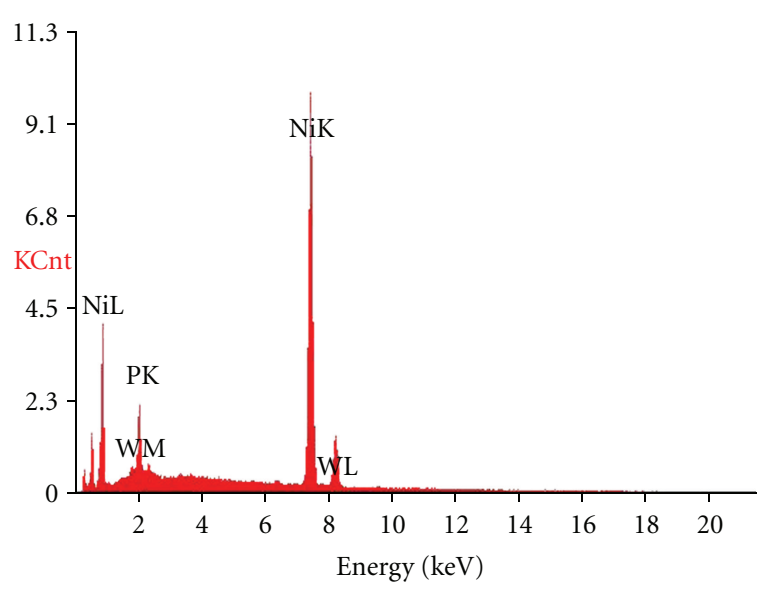

FIGURE 1: EDX spectra of coated surface.

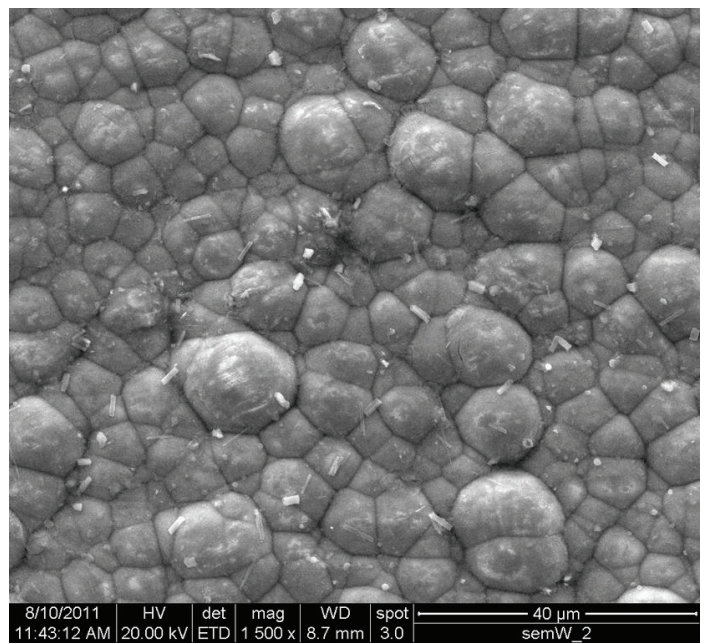

Figure 2: SEM image of Ni-P-W coated surface.

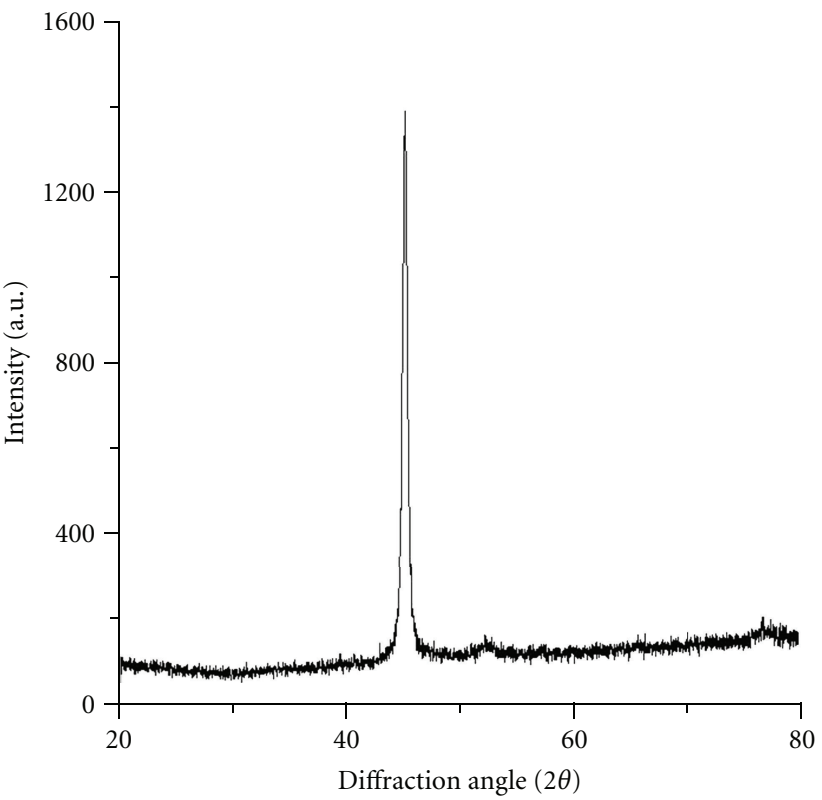

FIGURE 3: XRD plot of as deposited surface.
TABLE 3: Chemical composition and operating condition.

\begin{tabular}{lc}
\hline Bath constituents & Values \\
\hline Nickel sulphate $(\mathrm{g} / \mathrm{L})$ & $20-30$ \\
Sodium hypophosphite $(\mathrm{g} / \mathrm{L})$ & $14-20$ \\
Sodium citrate $(\mathrm{g} / \mathrm{L})$ & 35 \\
Ammonium sulphate $(\mathrm{g} / \mathrm{L})$ & 30 \\
Lactic acid $(\mathrm{g} / \mathrm{L})$ & 5 \\
Sodium tungstate $(\mathrm{g} / \mathrm{L})$ & $15-25$ \\
pH & $7-8$ \\
Temperature & $90 \pm 2{ }^{\circ} \mathrm{C}$ \\
Duration of coating & $3 \mathrm{hrs}$ \\
Bath volume $(\mathrm{mL})$ & 200 \\
\hline
\end{tabular}

TABLE 4: Experimental results for roughness parameters.

\begin{tabular}{|c|c|c|c|c|c|}
\hline Sample no. & $R_{a}(\mu \mathrm{m})$ & $R_{q}(\mu \mathrm{m})$ & $R_{\mathrm{sk}}$ & $R_{\mathrm{ku}}$ & $R_{\mathrm{sm}}(\mathrm{mm})$ \\
\hline 1 & 0.41 & 0.52 & 1.05 & 5.56 & 0.146 \\
\hline 2 & 0.43 & 0.57 & 0.65 & 6.71 & 0.133 \\
\hline 3 & 0.62 & 0.85 & 3.97 & 7.39 & 0.141 \\
\hline 4 & 0.41 & 0.53 & 1.1 & 6.77 & 0.183 \\
\hline 5 & 0.46 & 0.59 & 0.65 & 7.77 & 0.199 \\
\hline 6 & 0.46 & 0.61 & 1.95 & 5.26 & 0.169 \\
\hline 7 & 0.4 & 0.53 & 2.59 & 5.8 & 0.173 \\
\hline 8 & 0.43 & 0.59 & 3.04 & 7.03 & 0.153 \\
\hline 9 & 0.39 & 0.49 & 0.43 & 4.07 & 0.15 \\
\hline 10 & 0.35 & 0.44 & 0.59 & 3.52 & 0.226 \\
\hline 11 & 0.48 & 0.59 & 0.4 & 3.73 & 0.222 \\
\hline 12 & 0.39 & 0.57 & 2.17 & 5.9 & 0.167 \\
\hline 13 & 0.29 & 0.38 & 1.61 & 7.28 & 0.117 \\
\hline 14 & 0.63 & 0.75 & 1.12 & 5.79 & 0.183 \\
\hline 15 & 0.36 & 0.45 & 0.91 & 6.51 & 0.151 \\
\hline 16 & 0.61 & 0.73 & 1.07 & 6.68 & 0.055 \\
\hline 17 & 0.61 & 0.79 & 1.43 & 7.49 & 0.053 \\
\hline 18 & 0.62 & 0.8 & 0.9 & 5.34 & 0.058 \\
\hline 19 & 0.44 & 0.56 & 1.08 & 6.29 & 0.127 \\
\hline 20 & 0.45 & 0.59 & 1.22 & 6.86 & 0.065 \\
\hline 21 & 0.97 & 1.32 & 1.54 & 9.95 & 0.08 \\
\hline 22 & 0.45 & 0.58 & 1.08 & 7.91 & 0.081 \\
\hline 23 & 0.44 & 0.55 & 0.8 & 5.92 & 0.147 \\
\hline 24 & 0.76 & 1.08 & 3.07 & 6.63 & 0.149 \\
\hline 25 & 0.49 & 0.68 & 2.92 & 3.01 & 0.106 \\
\hline 26 & 0.41 & 0.52 & 1.08 & 9.16 & 0.093 \\
\hline 27 & 0.48 & 0.62 & 1.03 & 6.61 & 0.102 \\
\hline
\end{tabular}

amorphous behaviour but there is very small existence of crystalline peak which means the deposited surface is a mixture of crystalline and amorphous structure as shown in Figure 3. 
TABLE 5: $\mathrm{S} / \mathrm{N}$ ratios of different responses.

\begin{tabular}{|c|c|c|c|c|c|}
\hline Trial no. & $R_{a}$ & $R_{q}$ & $R_{\mathrm{sk}}$ & $R_{\mathrm{ku}}$ & $R_{\mathrm{sm}}$ \\
\hline 1 & 7.74432 & 5.67993 & -0.42379 & -14.90150 & 16.71294 \\
\hline 2 & 7.33063 & 4.88250 & 3.74173 & -16.53445 & 17.52297 \\
\hline 3 & 4.15217 & 1.41162 & -11.97581 & -17.36701 & 17.01562 \\
\hline 4 & 7.74432 & 5.51448 & -0.82785 & -16.61177 & 14.75098 \\
\hline 5 & 6.74484 & 4.58296 & 3.74173 & -17.80842 & 14.02294 \\
\hline 6 & 6.74484 & 4.29340 & -5.80069 & -14.41971 & 15.44227 \\
\hline 7 & 7.95880 & 5.51448 & -8.26600 & -15.26856 & 15.23908 \\
\hline 8 & 7.33063 & 4.58296 & -9.65747 & -16.93911 & 16.30617 \\
\hline 9 & 8.17871 & 6.19608 & 7.33063 & -12.19189 & 16.47817 \\
\hline 10 & 9.11864 & 7.13095 & 4.58296 & -10.93085 & 12.91783 \\
\hline 11 & 6.37518 & 4.58296 & 7.95880 & -11.43418 & 13.07294 \\
\hline 12 & 8.17871 & 4.88250 & -6.72919 & -15.41704 & 15.54567 \\
\hline 13 & 10.75204 & 8.40433 & -4.13652 & -17.23785 & 18.63628 \\
\hline 14 & 4.01319 & 2.49877 & -0.98436 & -15.25357 & 14.75098 \\
\hline 15 & 8.87395 & 6.93575 & 0.81917 & -16.27162 & 16.42046 \\
\hline 16 & 4.29340 & 2.73354 & -0.58768 & -16.49553 & 25.19275 \\
\hline 17 & 4.29340 & 2.04746 & -3.10672 & -17.48964 & 25.51448 \\
\hline 18 & 4.15217 & 1.93820 & 0.91515 & -14.55083 & 24.73144 \\
\hline 19 & 7.13095 & 5.03624 & -0.66848 & -15.97301 & 17.92393 \\
\hline 20 & 6.93575 & 4.58296 & -1.72720 & -16.72648 & 23.74173 \\
\hline 21 & 0.26457 & -2.41148 & -3.75041 & -19.95646 & 21.93820 \\
\hline 22 & 6.93575 & 4.73144 & -0.66848 & -17.96353 & 21.83030 \\
\hline 23 & 7.13095 & 5.19275 & 1.93820 & -15.44643 & 16.65365 \\
\hline 24 & 2.38373 & -0.66848 & -9.74277 & -16.43027 & 16.53627 \\
\hline 25 & 6.19608 & 3.34982 & -9.30766 & -9.57133 & 19.49388 \\
\hline 26 & 7.74432 & 5.67993 & -0.66848 & -19.23791 & 20.63034 \\
\hline 27 & 6.37518 & 4.15217 & -0.25674 & -16.40403 & 19.82800 \\
\hline
\end{tabular}

\section{Analysis of Results}

3.1. Signal-to-Noise Ratio. Some measurable responses to the system output during the operation of any engineering system or process are called performance characteristics. These may be applied to the evaluation of the system or process. Genichi Taguchi converted the responses into the signal-to-noise $(\mathrm{S} / \mathrm{N})$ ratio to make an evaluation. There are usually three types of $\mathrm{S} / \mathrm{N}$ ratios, namely, target-the-best, larger-the-better, and smaller-the-better. In this study, the five responses are the five roughness parameters which are to be optimized. From tribological application point of view, $R_{a}, R_{q}$, and $R_{\mathrm{sm}}$ need to be minimized while $R_{\mathrm{sk}}$ needs to be targeted to zero, and $R_{\mathrm{ku}}$ needs to be targeted to 3 (Gaussian values). In the present case, it is observed from Table 4 that all $R_{\mathrm{sk}}$ values are positive, and $R_{\mathrm{ku}}$ values are greater than 3 . Hence, all the five roughness parameters are optimized using the lower-the-better principle given by the formula:

$$
\mathrm{S} / \mathrm{N}=-10 \log \left(\frac{1}{n} \sum_{i=1}^{n} \frac{1}{y_{i}^{2}}\right),
$$

where, $y_{i}$ is the measured value of responses and $n$ is the number of observations. The $\mathrm{S} / \mathrm{N}$ ratios of the responses are shown in Table 5.
3.2. WPCA Method. The weighted principal component analysis is a multivariate statistical method that selects a small number of components to account for the variance of original multiresponse. The technique was first introduced by Pearson and then further developed by Hotelling [17]. The procedure is described as follows:

(1) the original multiresponse array for $m$ number of test trials and $n$ number of responses is expressed as

$$
\mathrm{X}=\left[\begin{array}{ccccc}
x_{1}(1) & x_{1}(2) & \cdots & \cdots & x_{1}(n) \\
x_{2}(1) & x_{2}(2) & \cdots & \cdots & x_{2}(n) \\
\vdots & \vdots & \cdots & \cdots & \vdots \\
\vdots & \vdots & \cdots & \cdots & \vdots \\
x_{m}(1) & x_{m}(2) & \cdots & \cdots & x_{m}(n)
\end{array}\right]
$$

where, $x$ is the $\mathrm{S} / \mathrm{N}$ ratio of each response.

(2) The $\mathrm{S} / \mathrm{N}$ ratio is normalized using the following formula to get rid of the difference between units

$x_{i}^{*}(j)=\frac{x_{i}(j)-x_{i}(j)_{\min }}{x_{i}(j)_{\max }-x_{i}(j)_{\min }} \quad j=1,2, \ldots, m$,

where, $x_{i}^{*}$ is the normalized value of response, $x_{i}(j)_{\max }$ and $x_{i}(j)_{\min }$ are the maximum and minimum of $x_{i}(j)$, respectively.

The normalized multiresponse array $X^{*}$ can be expressed as

$$
X^{*}=\left[\begin{array}{ccccc}
x_{1}^{*}(1) & x_{1}^{*}(2) & \cdots & \cdots & x_{1}^{*}(n) \\
x_{2}^{*}(1) & x_{2}^{*}(2) & \cdots & \cdots & x_{2}^{*}(n) \\
\vdots & \vdots & \cdots & \cdots & \vdots \\
\vdots & \vdots & \cdots & \cdots & \vdots \\
x_{m}^{*}(1) & x_{m}^{*}(2) & \cdots & \cdots & x_{m}^{*}(n)
\end{array}\right] .
$$

(3) The eigenvalues and eigenvectors are evaluated from the covariance matrix obtained from the normalized data. The covariance matrix is calculated as

$$
A=\left[\begin{array}{ccccc}
\operatorname{variance}(1) & \operatorname{cov}(1,2) & \cdots & \cdots & \operatorname{cov}(1, n) \\
\operatorname{cov}(2,1) & \operatorname{variance}(2) & \cdots & \cdots & \operatorname{cov}(2, n) \\
\vdots & \vdots & \ldots & \cdots & \vdots \\
\vdots & \vdots & \ldots & \cdots & \vdots \\
\operatorname{cov}(n, 1) & \operatorname{cov}(n, 2) & \cdots & \cdots & \operatorname{variance}(n)
\end{array}\right] .
$$

Then using the equation

$$
[A-\lambda I] *[V]=0 .
$$

The eigenvalues $(\lambda)$ and eigenvector $V=$ $\left[\begin{array}{lllll}V_{1} & V_{2} & \cdots & \cdots & V_{n}\end{array}\right]^{T}$ is computed, imposing the condition $\sum_{i=1}^{n} V_{i}^{2}=1$.

The eigenvalue, eigenvector, and explained variation for this study are shown in Table 6. 
TABLE 6: Eigenvalue, explained variation, and eigenvector for the present study.

\begin{tabular}{lccc}
\hline Principal component & Eigenvalue & Proportion of explained variation & Eigenvector \\
\hline First & 2.569931 & 0.51398 & {$[-0.564327,-0.576643,-0.307783,-0.331322,0.380149]$} \\
Second & 0.974719 & 0.19495 & {$[-0.303541,-0.335006,-0.212192,0.677279,-0.540279]$} \\
Third & 0.885494 & 0.17709 & {$[0.281791,0.155927,-0.850684,-0.295820,-0.291732]$} \\
Fourth & 0.561881 & 0.11237 & {$[0.177131,0.136357,-0.357452,0.586516,0.691562]$} \\
Fifth & 0.007975 & 0.00159 & {$[-0.691821,0.715784,-0.093856,0.002778,-0.014805]$} \\
\hline
\end{tabular}

TABLE 7: Scaled S/N ratio and MPI values.

\begin{tabular}{lcccccc}
\hline \multirow{2}{*}{ Trial no. } & \multicolumn{5}{c}{ Scaled S/N ratio } \\
& $R_{a}$ & $R_{q}$ & $R_{\text {sk }}$ & $R_{\text {ku }}$ & $R_{\text {sm }}$ & MPI \\
\hline 1 & 0.71321 & 0.74811 & 0.57950 & 0.48675 & 0.30128 & -0.64105 \\
2 & 0.67376 & 0.67438 & 0.78845 & 0.32951 & 0.36558 & -0.67681 \\
3 & 0.37069 & 0.35347 & 0.00000 & 0.24934 & 0.32531 & -0.18465 \\
4 & 0.71321 & 0.73281 & 0.55923 & 0.32206 & 0.14553 & -0.64228 \\
5 & 0.61791 & 0.64669 & 0.78845 & 0.20684 & 0.08773 & -0.68157 \\
6 & 0.61791 & 0.61992 & 0.30977 & 0.53314 & 0.20041 & -0.48112 \\
7 & 0.73366 & 0.73281 & 0.18610 & 0.45141 & 0.18428 & -0.50100 \\
8 & 0.67376 & 0.64669 & 0.11630 & 0.29055 & 0.26899 & -0.41577 \\
9 & 0.75463 & 0.79583 & 0.96849 & 0.74766 & 0.28264 & -0.82835 \\
10 & 0.84425 & 0.88227 & 0.83065 & 0.86909 & 0.00000 & -0.86294 \\
11 & 0.58266 & 0.64669 & 1.00000 & 0.82062 & 0.01231 & -0.77824 \\
12 & 0.75463 & 0.67438 & 0.26319 & 0.43711 & 0.20861 & -0.51526 \\
13 & 1.00000 & 1.00000 & 0.39325 & 0.26178 & 0.45397 & -0.70548 \\
14 & 0.35744 & 0.45399 & 0.55138 & 0.45285 & 0.14553 & -0.45409 \\
15 & 0.82092 & 0.86422 & 0.64185 & 0.35482 & 0.27806 & -0.73192 \\
16 & 0.38416 & 0.47569 & 0.57127 & 0.33326 & 0.97446 & -0.37706 \\
17 & 0.38416 & 0.41226 & 0.44491 & 0.23753 & 1.00000 & -0.30223 \\
18 & 0.37069 & 0.40216 & 0.64666 & 0.52052 & 0.93784 & -0.38825 \\
19 & 0.65472 & 0.68860 & 0.56722 & 0.38357 & 0.39741 & -0.58723 \\
20 & 0.63611 & 0.64669 & 0.51411 & 0.31102 & 0.85927 & -0.49255 \\
21 & 0.00000 & 0.00000 & 0.41262 & 0.00000 & 0.71609 & -0.07800 \\
22 & 0.63611 & 0.66041 & 0.56722 & 0.19190 & 0.70753 & -0.53232 \\
23 & 0.65472 & 0.70307 & 0.69798 & 0.43428 & 0.29657 & -0.65586 \\
24 & 0.20207 & 0.16115 & 0.11202 & 0.33954 & 0.28725 & -0.12666 \\
25 & 0.56558 & 0.53267 & 0.13385 & 1.00000 & 0.52205 & -0.34424 \\
26 & 0.71321 & 0.74811 & 0.56722 & 0.06919 & 0.61227 & -0.58982 \\
27 & 0.58266 & 0.60686 & 0.58788 & 0.34207 & 0.54857 & -0.53055 \\
\hline & & & & & & \\
& & & &
\end{tabular}

TABLE 8: Level averages on MPI.

\begin{tabular}{lccc}
\hline Factor & Level 1 & Level 2 & Level 3 \\
\hline A & -0.5614 & -0.56839 & -0.43747 \\
B & -0.53519 & -0.55681 & -0.47525 \\
C & -0.57707 & -0.56077 & -0.42942 \\
\hline
\end{tabular}

(4) The principal components are obtained using the following equation

$$
Y_{m, n}=X_{m, n}^{*} \times V_{n, n}
$$

Finally, the multiresponse performance index (MPI) is calculated for $j$ th trial by using the formula:

$$
\mathrm{MPI}_{j}=\sum_{i=1}^{n} W_{i} \times Y_{i j}
$$

where, $j=1,2, \ldots, m$.

Here, $W_{i}$ is the proportion of overall variance of the responses explained by $i$ th principal component and $Y_{i j}$ is the $i$ th principal component corresponding to $j$ th trial. Larger value of MPI will imply better quality.

The scaled $\mathrm{S} / \mathrm{N}$ ratio value and the computed MPI for each trial are shown in Table 7 . The level averages on the MPI are given in Table 8. As the larger value of MPI indicates better quality, the optimum combination of process parameters is obtained as $\mathrm{A} 3 \mathrm{~B} 3 \mathrm{C} 3$ considering the maximum value of level average of each factor.

3.3. Analysis of Variance (ANOVA). Analysis of variance is carried out on the MPI values shown in Table 9. The result reveals that among all the three factors the concentration of nickel source $(A)$ and the concentration of tungsten source (C) significantly affect the roughness characteristics, and among the interactions the interaction between reducing agent concentration and tungsten concentration is most significant.

\section{Confirmation Test}

A confirmation test is carried out in order to validate the result. A comparison between the initial parameter combination and optimum combination is shown in Table 10. From the table, it is clear that the total $\mathrm{S} / \mathrm{N}$ ratio of optimum combination is higher than the initial parameter combination. It is well known that regardless of the category of the performance characteristics, a higher $\mathrm{S} / \mathrm{N}$ ratio always corresponds to a better performance. Hence, the result of confirmation test ensures the better performance of the optimum design.

\section{Conclusion}

In the present study, weighted principal component analysis (WPCA) is used to optimize the coating process parameters (concentration of nickel source, concentration of reducing agent, and concentration of tungsten source) together in order to optimize multiple roughness parameters $\left(R_{a}, R_{q}\right.$, 
TABLE 9: ANOVA on MPI.

\begin{tabular}{|c|c|c|c|c|c|}
\hline Source & $\mathrm{DF}$ & Sum of square & Mean of square & $F$-ratio & Contribution $\%$ \\
\hline A & 2 & 0.09764 & 0.04882 & $2.55^{*}$ & 9.18 \\
\hline B & 2 & 0.03214 & 0.01607 & 0.84 & 3.02 \\
\hline $\mathrm{C}$ & 2 & 0.11796 & 0.05898 & $3.08^{*}$ & 11.09 \\
\hline $\mathrm{A} * \mathrm{~B}$ & 4 & 0.21563 & 0.05391 & 2.81 & 20.28 \\
\hline $\mathrm{A} * \mathrm{C}$ & 4 & 0.10983 & 0.02746 & 1.43 & 10.33 \\
\hline $\mathrm{B} * \mathrm{C}$ & 4 & 0.33686 & 0.08421 & $4.39 * *$ & 31.68 \\
\hline Error & 8 & 0.15339 & 0.01917 & 14.42 & \\
\hline Total & 26 & 1.06344 & 100.00 & & \\
\hline
\end{tabular}

${ }^{*}$ Significant at $75 \%$ confidence level.

$* *$ Significant at $95 \%$ confidence level.

TABLE 10: Results of confirmation test.

\begin{tabular}{lcc}
\hline Responses & $\begin{array}{c}\text { Initial combination } \\
\mathrm{A} 2 \mathrm{~B} 2 \mathrm{C} 2\end{array}$ & $\begin{array}{c}\text { Optimum combination } \\
\mathrm{A} 3 \mathrm{~B} 3 \mathrm{C} 3\end{array}$ \\
\hline$R_{a}$ & 0.63 & 0.48 \\
$R_{q}$ & 0.75 & 0.62 \\
$R_{\mathrm{sk}}$ & 1.12 & 1.03 \\
$R_{\mathrm{ku}}$ & 5.79 & 6.61 \\
$R_{\mathrm{sm}}$ & 0.18 & 0.102 \\
\hline Total S/N ratio & 5.02501 & 13.69456 \\
\hline
\end{tabular}

Improvement of $\mathrm{S} / \mathrm{N}$ ratio is $8.66955 \mathrm{~dB}$.

$R_{\mathrm{sk}}, R_{\mathrm{ku}}$, and $\left.R_{\mathrm{sm}}\right)$ of Ni-P-W coating. The optimal combination of coating parameters is obtained as A3B3C3. ANOVA result indicates that concentration of tungsten source $(C)$ is the most important parameter that significantly affects the roughness characteristics at a confidence level of $75 \%$. Also, the concentration of nickel source is quite significant at the same level of confidence. The improvement of the $\mathrm{S} / \mathrm{N}$ ratio from the initial condition to the optimal condition is observed. From the EDX analysis, it is clear that the coating is pure ternary and consists of nickel, phosphorous, and tungsten. The XRD plots reveal that the coating is a mixture of amorphous and crystalline structure in the as deposited condition. From the surface morphology captured by SEM, it is seen that there are many globular particles on the surface of the substrate with no surface damage. Also, the coating is dense and with low porosity.

\section{References}

[1] A. Brenner and G. E. Riddell, "Nickel plating by chemical reduction," US Patent, US2532282, 1950.

[2] P. Sahoo and S. K. Das, "Tribology of electroless nickel coatings - a review," Materials and Design, vol. 32, no. 4, pp. 1760-1775, 2011.

[3] P. Sahoo, "Optimization of electroless Ni-P coatings based on multiple roughness characteristics," Surface and Interface Analysis, vol. 40, no. 12, pp. 1552-1561, 2008.

[4] S. K. Tien, J. G. Duh, and Y. I. Chen, "The influence of thermal treatment on the microstructure and hardness in electroless Ni-P-W deposit," Thin Solid Films, vol. 469-470, pp. 333-338, 2004.
[5] M. Palaniappa and S. K. Seshadri, "Friction and wear behavior of electroless Ni-P and Ni-W-P alloy coatings," Wear, vol. 265, no. 5-6, pp. 735-740, 2008.

[6] Y. Y. Tsai, F. B. Wu, Y. I. Chen, P. J. Peng, J. G. Duh, and S. Y. Tsai, "Thermal stability and mechanical properties of Ni-WP electroless deposits," Surface and Coatings Technology, vol. 146-147, pp. 502-507, 2001.

[7] H. S. Yu, S. F. Luo, and Y. R. Wang, "A comparative study on the crystallization behavior of electroless $\mathrm{Ni}-\mathrm{P}$ and $\mathrm{Ni}-\mathrm{Cu}-\mathrm{P}$ deposits," Surface and Coatings Technology, vol. 148, no. 2-3, pp. 143-148, 2001.

[8] Y. Liu and Q. Zhao, "Study of electroless Ni-Cu-P coatings and their anti-corrosion properties," Applied Surface Science, vol. 228, no. 1-4, pp. 57-62, 2004.

[9] J. Novakovic, P. Vassiliou, K. Samara, and T. Argyropoulos, "Electroless $\mathrm{NiP}_{-} \mathrm{TiO}_{2}$ composite coatings: their production and properties," Surface and Coatings Technology, vol. 201, no. 3-4, pp. 895-901, 2006.

[10] W. Chen, W. Gao, and Y. He, "A novel electroless plating of Ni-P-TiO ${ }_{2}$ nano-composite coatings," Surface and Coatings Technology, vol. 204, no. 15, pp. 2493-2498, 2010.

[11] F. B. Wu, S. K. Tien, W. Y. Chen, and J. G. Duh, "Microstructure evaluation and strengthening mechanism of Ni-P-W alloy coatings," Surface and Coatings Technology, vol. 177-178, pp. 312-316, 2004.

[12] S. K. Tien, J. G. Duh, and Y. I. Chen, "Structure, thermal stability and mechanical properties of electroless Ni-P-W alloy coatings during cycle test," Surface and Coatings Technology, vol. 177-178, pp. 532-536, 2004.

[13] F. Pearlstein, R. F. Weightman, and R. Wick, Metal Finishing, vol. 61, pp. 77-81, 1963.

[14] A. Brenner, Electro Deposition of Alloys, vol. 2, Academic Press, New York, NY, USA, 1963.

[15] E. S. Gadelmawla, M. M. Koura, T. M. A. Maksoud, I. M. Elewa, and H. H. Soliman, "Roughness parameters," Journal of Materials Processing Technology, vol. 123, no. 1, pp. 133-145, 2002.

[16] W. Riedel, Electroless Nickel Plating, Finishing Publications, Stevenage, UK, 1991.

[17] C. P. Fung and P. C. Kang, "Multi-response optimization in friction properties of PBT composites using Taguchi method and principle component analysis," Journal of Materials Processing Technology, vol. 170, no. 3, pp. 602-610, 2005. 

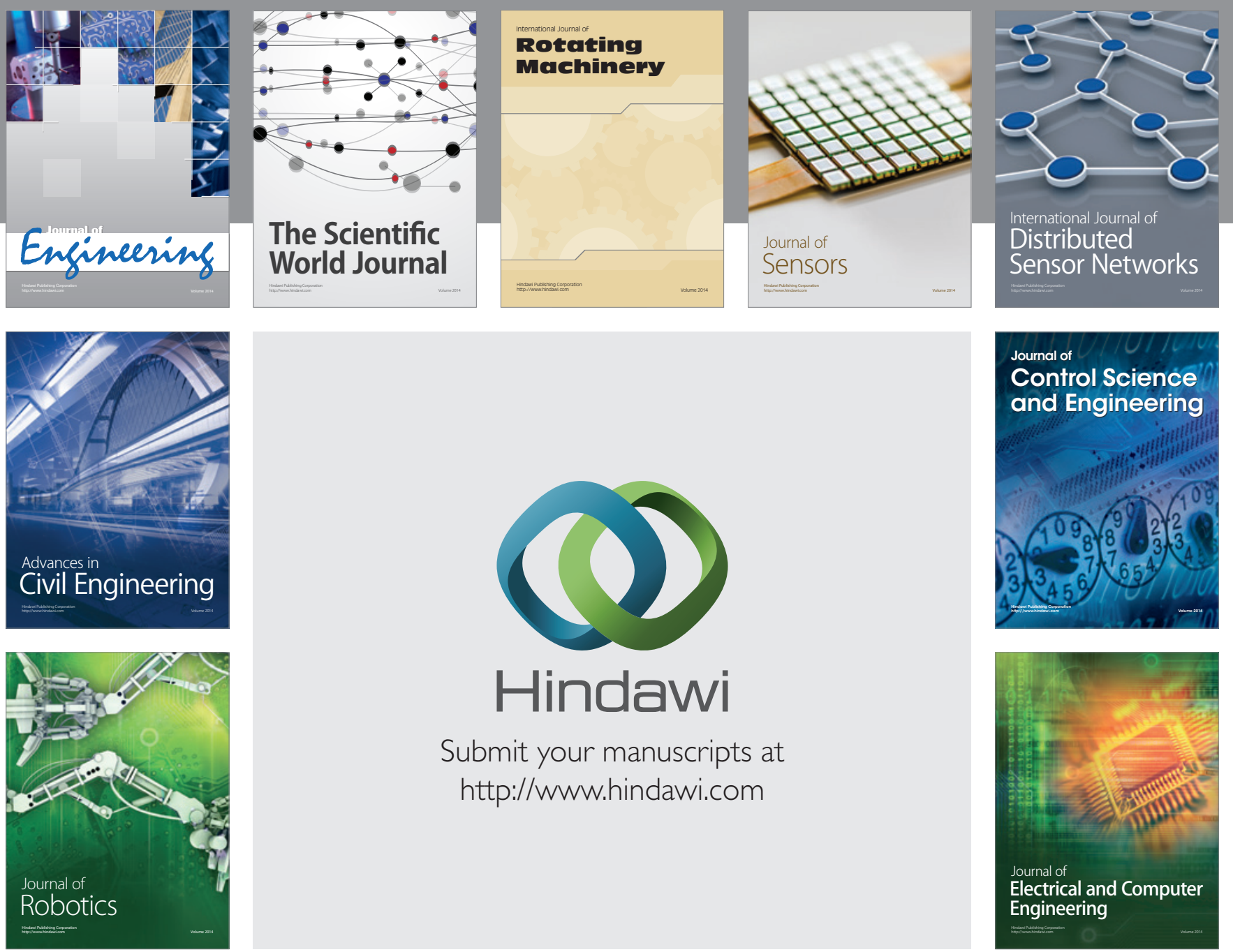

Submit your manuscripts at

http://www.hindawi.com
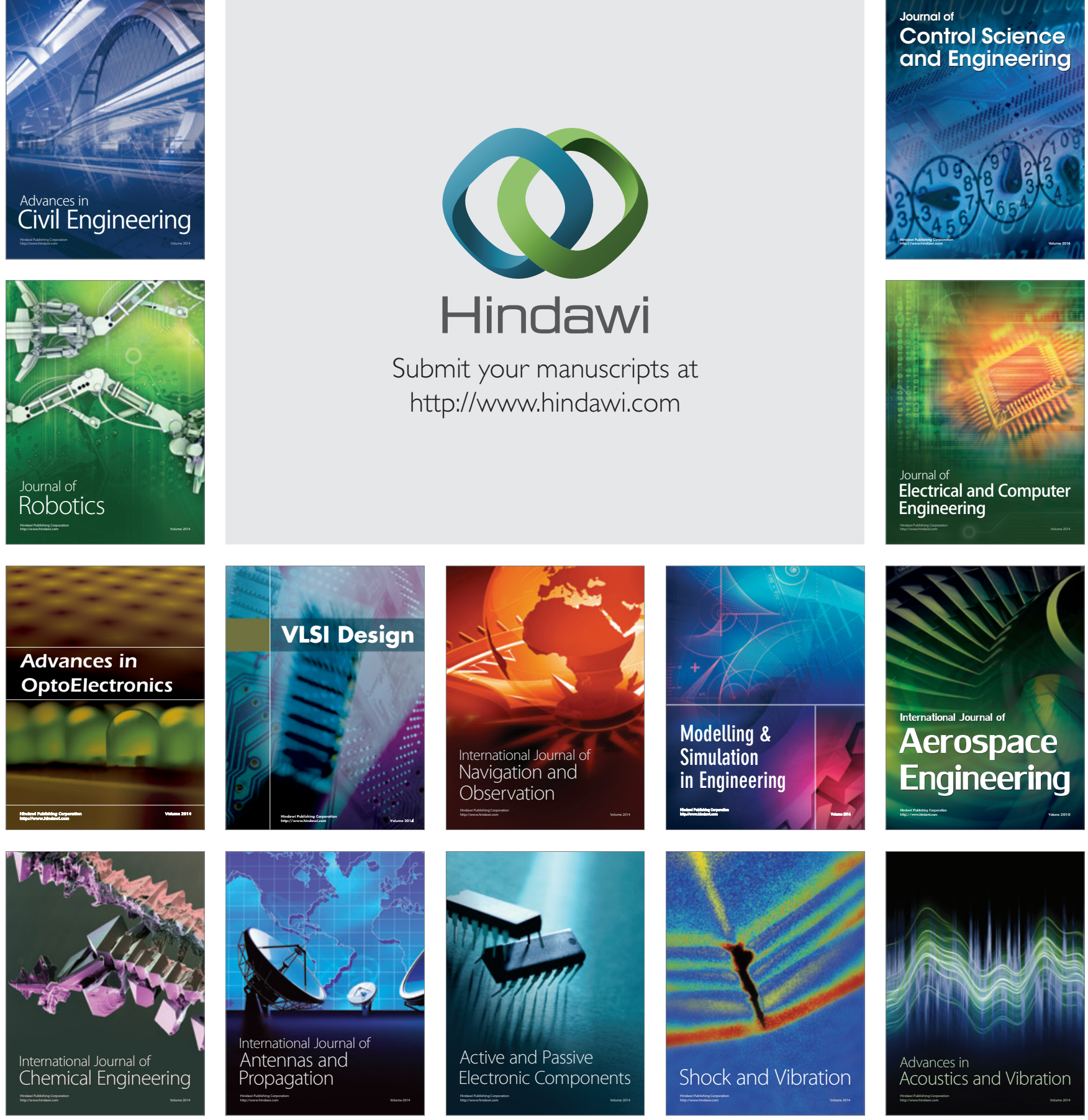